Elsevier Editorial System(tm) for Fusion Engineering and Design

Manuscript Draft

Manuscript Number: FUSENGDES-D-06-00150R1

Title: Quality assurance of aluminium weld seams and cast casings of the W7-X coils

Article Type: "SOFT 24th Special Issue Paper"

Section/Category: Special Issue - SOFT-24 (Proceedings of the 24th Symposium on Fusion Technology)

Keywords: Aluminum weld seams; cast stainless steel, Quality Assurance, NDT

Corresponding Author: Mr Michael Schroeder,

Corresponding Author's Institution: Max-Planck-Institute for Plasmaphysics

First Author: Michael Schroeder

Order of Authors: Michael Schroeder; Jens Holluba; Katrin Heyn 


\title{
Quality assurance of aluminium weld seams and cast casings of the W7-X coils
}

\author{
M. Schröder, J. Holluba, K. Heyn * \\ Max-Planck-Institut für Plasmaphysik, Euratom Association \\ Teilinstitut Greifswald, Wendelsteinstr. 1, D-17491 Greifswald, Germany \\ *Babcock Noell GmbH, Alfred-Nobel-Str. 20, D-97080 Würzburg \\ Corresponding author. Tel.: +49-3834-882351; Fax: +49-3834-882009; \\ E-mail address: michael.schroeder@ipp.mpg.de
}

\begin{abstract}
The WENDELSTEIN 7-X stellarator is the next step device in the stellarator line of IPP Garching. It is presently being as sembled in the branch institute of IPP at Greifswald. The central part of $\mathrm{W} 7-\mathrm{X}$ is the superconducting magnet system. It comprises 50 non-planar and 20 plan ar coils. This contribution outlines for two critical examples of the magnet system the quality assurance measures applied, namely for the aluminium weld seams at the superconductor cable during the assembly and for the cast steel casings of the non-planar coils during manufacture.
\end{abstract}

Keywords: Aluminium weld seams; cast stainless steel, quality assurance, NDT

\section{Introduction}

The superconducting magnet system of the WENDELSTEIN 7-X(W7-X) stellarator comprises 50 non-planar (five types) and 20 planar (two types) coils. A detailed description of the 
magnet system can be found in [1]. Each group of ten equal coils is connected to the respective current leads by a superconducting bus system. The connections between the coils and the bus system are made with special transition pieces consisting of an Aluminium/Stainless Steel diffusion bonded piece. These pieces must be welded on one side to the aluminium jacket of the superconductor.

In order to cope with the tremendous electro-magn etic loads on the winding packages (WPs), the WPs are put into stainless steel coil casings. The casings are made of cast material which in some areas showed unacceptable defects which had to be repaired even after some coils already had been assembled.

In the following the quality assurance measures for these two different topics are outlined.

\section{Quality assurance of aluminium weld seams}

\subsection{Significance and requirements of the weld seams}

The superconductor used in the coils and in the busbar system consists of 243 strands composed of $\mathrm{NbTi}$ filaments and copper stabilizer. The strands are wound to a cable and are coextruded with an AlMgSi0,5 billet to form the aluminium jacket, which stabilizes the cable against the Lorentz forces. Liquid helium will flow through the voids between the strands and the jacket to cool the conductor to approx. 4K (see Fig. 1). The non-planar and planar coils of W7-X consist of winding packages made from six and three winding layers. The connections of the winding layers inside a coil are made by the manufacturer. The interlayer joint housings are composed of aluminium and are welded to the conductor jacket. The qualification of these welds by the manufacturer has already shown that it is very difficult to get defect free welds. For the connection of the coils amongst each other and also for the connection of the bus system across the module separation planes welded jo ints are used with austenitic steel housings because of a possibly increased pressure level inside these joints during a quench. The con- 
nections between the joint housings and the Al-jacket are made by Aluminium/Stainless Steel diffusion bonded transition pieces. The weld seams between the superconductor jacket and the transition pieces are welded during the assembly of W7-X.

All in all 382 transition pieces have to be welded along the four cable jacket sides during the assembly. Each of the weld seams has to fulfil the following requirements:

- Helium leak tight for a pressure up to $170 \mathrm{~b}$ ar, depending on the position in the bus

- Helium leak tight after 50 thermal cycles between ambient temperature and $4 \mathrm{~K}$

- Helium leak tight for a minimum of 15 years of operation with thousands of magnetic load cycles

\subsection{Conditions for the manufacturing of the weld sea ms}

Although the weld seams are in principle simple fillet welds (see Fig. 2) their manufacture is not without risk due to a number of constraints and boundary conditions:

- Temperature limitation: The main hazard is to exceed a temperature of the superconductor jacket during welding of $500^{\circ} \mathrm{C}$, so that the superconductor will degrade.

- Geometrical deviation: Because of the tolerances of the production, the dimension of the cable jacket cross section can vary from $15.85 \mathrm{~mm}$ to $16.05 \mathrm{~mm}$. The superconductor of the coils is bent during coil production and tests. Since the dimensions of the transition piece are fixed, the welding gap varies accordingly (see Fig. 3).

- Contaminations: The conductor jacket can be contaminated during the production of the superconductor, duringthe insulation process, and the various handlings (by the coil manufacturer, coil test, transport, storing, and ass embly preparation at IPP). These contaminations could be the reason for the creation of poro sity by hydrogen during welding.

- Accessibility: Access to the welds is partly restricted because of geometric constraints.

- Welding in difficult positions: The seams have to be welded in different positions. Also the overhead position is necessary. 


\subsection{Qualification of the weld seams}

\subsubsection{Background}

At the beginning of the project a welding procedure for the Aluminium welds of the superconductor was developed which was mainly influenced by the need of the temperature restriction on the inside of the conductor jacket. Only very few samples were welded and the main monitoring was measurement of the temperature at the conductor surface and visual inspec-

tion of the weld seam. During the course of the coil manufacture and in preparation of the coil connection with the bus system, much more samples were produced and investigated using also destructive tests by cutting the welds and preparing macros. It turned out that the reproducibility of a good weld quality does depend on many parameters and a dedicated qualification program was started to figure out, what types of failure occur and how to prevent these. The qualification was finished in December 2005 with the welding of five qualification samples, which fulfilled the acceptance criteria (see 2.3.3). This resulted in a Welding Procedure Specification (WPS) which is now the basis for the work.

\subsubsection{Weld seam failures and measures for prevention}

During manufacture of test samples a number of weld seam imperfections occurred amongst which pores and cracks in the root area are most difficult to avoid. When welding aluminium, pores are always produced from hydrogen in the weld metal; cracks are mostly hot cracks. Table 1 gives a summary of the imperfections found, the possible reasons for their occurrence and the measures to avoid them.

\subsubsection{Acceptance criteria}

According to the standard (EN 30042, class B), which is required for high quality welds, certain imperfection are not allowed or their size is restricted to certain values. Since the main 
criterion for the quality of the weld is the leak tightness under all circumstances, a test program was set up for the qualification of the welds. The samples were tested according to the following scheme: He leak test (30 bar), Temperature cycling (10 times RT - $\mathrm{LN}_{2}-\mathrm{RT}$ ), Pressure test ( 3 times 250 bar water) and He leak test (30 bar). Afterwards the samples have been cut and macros have been prepared. Typical defects are shown in Figs. 6-8. Based on this qualification program working weld samples showing these imperfections will be accepted. This qualification will now be extended to larger imperfections in order to get a feeling about the critical size and the safety margin built in into these criteria.

\subsection{Quality assurance during asse mbly}

The non-destructive testing of the welds to find the typical imperfections is not possible. Since the actual weld can only be inspected visually and leak checked, the destructive inspection of the weld can only be carried out on proof samples. To consider all factors (condition of the superconductor, accessibility, ambient conditions, daily ability of the welder) a proof sample is produced before welding on the real coil. The welding of the proof sample is always done under the same conditions as at the coil. This sample is investigated within some hours by preparing four macros. If the macros fulfil the specification, the welding is released, if not, another sample must be prepared. Immediately before the welding at the component a manual skill sample is welded too in order to train all welding steps for the last time. If the samples are successfully manufactured and visually inspected, the welding on the component is released. The results of the tests are documented and the samples are stored.

\section{Quality assurance of cast coil casings}

\subsection{Backgound}

The winding packages of the non-planar coils are embedded in casings made of cast austenitic steel (1.3960). The casings have to support the winding packages against the magnetic forces. 
A casing consists of two halves. Each half ring is cast in one piece. This production method has been chosen because of economic reasons. After casting the casings are solution annealed and machined. After the embedding of the winding package the halves are welded together along the circumference. Additional supports made of cast or forged steel are welded to the coil casing. The last step is the final machining of the coil casing.

\subsection{Applications and limitations of NDT methods}

Accord ing to the specification the quality of the cast steel for the casings has to fulfil the acceptance criteria DIN1690-ES3-RV3 in the body and DIN1690-ES2-RV2 in welding areas. To find casting defects non-destructive testing methods are used. Penetrant testing (PT) and radiographic testing (RT) are the usual methods.

PT is used to detect surface imperfections. PT can be used only after the machining of the casing because it is necessary to have a sufficiently smooth surface. If surface defects have been found, they have been repaired by grinding and built-up welding.

To find volume failures (especially shrinkage holes), for the radiographic testing (RT) at first

a x-ray tube $(300 \mathrm{kV})$ was used. However only after some coils have been already completed and finally machined the following problems emerged:

- Only wall thicknes ses up to approx. $70 \mathrm{~mm}$ could be tested, but there are some regions in the coil casing (see Fig. 9) where the thickness is up to $300 \mathrm{~mm}$.

- The dendritic coarse grains (see Fig. 10) of the austen itic casting create (at low x-ray energies) microstructure indications on the x-ray film, which can cover real failures.

These problems could be solved by x-ray with increased energy. Therefore, on all the coil casings half rings and also the already manufactured coils were $100 \%$ x-rayed by LINAC with en ergies of up to $8 \mathrm{MeV}$. Because of the size of the coils, the complicated geometry and the large wall thickness differences the LINAC testing is very complex. 
The possibility to test the casings by ultrasonic (UT) was also investigated. Again, for UT the complicated geometry and the coarse dendritic structure are a problem. Thereby the coupling of the probe is difficult and mostly the back plane echo could not be found. Furthermore the dentritic coarse grains create the appearance of high scattered energy, absorption, sound deflection and anisotropy of the sound velocity, so that UT is almost impossible. Only near the surface (depth 2-10 $\mathrm{mm}$ ) imperfections were detectable, but even an approximate determination of their sizes was not possible. Nevertheless UT is used for the wall thickn ess measurement on completed coils.

\subsection{Evaluation of the LINAC results}

After the LINAC-tests a working group with experts of the coil manufacturer BNG, of IPP, as well as external experts have evaluated all imperfections and have looked for practicable and technically reasonable decisions ( to repair, to reduce or to leave). These decisions were based on the consideration of

- the calculated stresses

- results of additional investigations at core borings (macros, tensile tests)

- estimation of the effect of welding repairs, e.g. concerning welding distortion.

Despite these efforts, at RT acceptable or not detectable volume failures became unaccep table surface failures after machining since the specification of V3 was sometimes not consistent with the demand for smoothly machined surfaces or undamaged threads. Therefore, additional repairs were partly necessary at ready-made coils.

\section{Conclusion}

The manufacture of the aluminium welds at the cable jacket is a special process which is influenced by a number of effects. Proof samples are welded, which conform as far as possible with the real component. By testing these samples under actual operating conditions accep- 
tance criteria for these welds were found. In future more tests will be performed to find out, what is the reliability of welding seams with larger imperfections than those being accepted so far. This may reduce the effort and increase the confidence in the process.

Cast austenitic steel is the preferred material for the coil casings because it is rather economic to manufacture the complex geometry in this way. In addition, this steel has good mechanical properties at low temperature and good weldability. However, since it has normally more and larger defects than forged or rolled material, the effort for non-destructive testing and additional repair work might be quite high. Acceptance criteria should specified as exactly as possible.

\section{References}

[1]: M. Wanner, Experience gained during Manufacture and Testing of the W7-X Superconducting Magnets, this conference

[2]: F. Schauer, Status of WENDELSTEIN 7-X Construction, this conference

[3]: K. Heyn, The integration of SME's into fusion projects - especially for the manufacturing of components for W-7X 


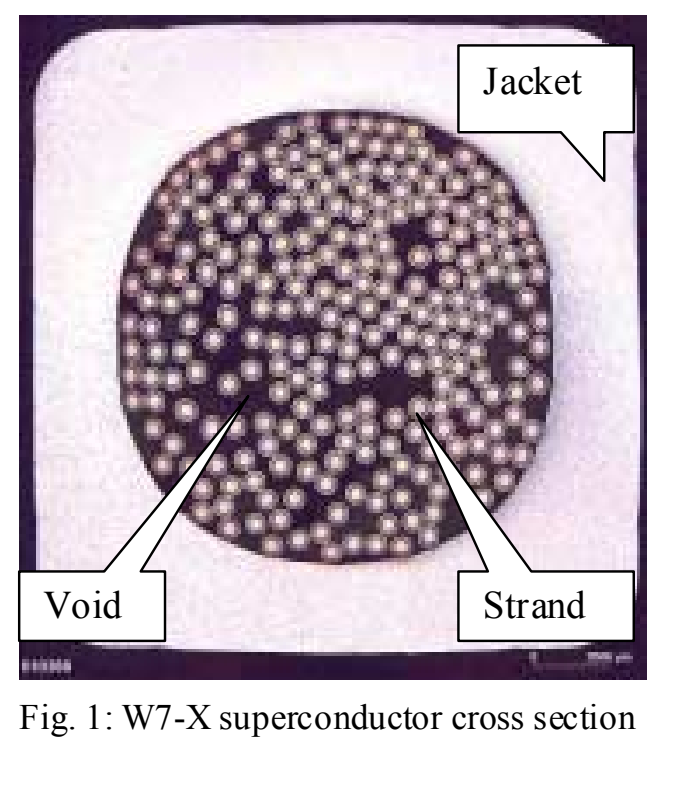

Figure

.

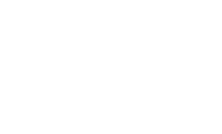

(

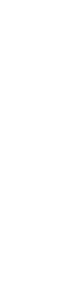

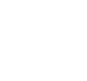
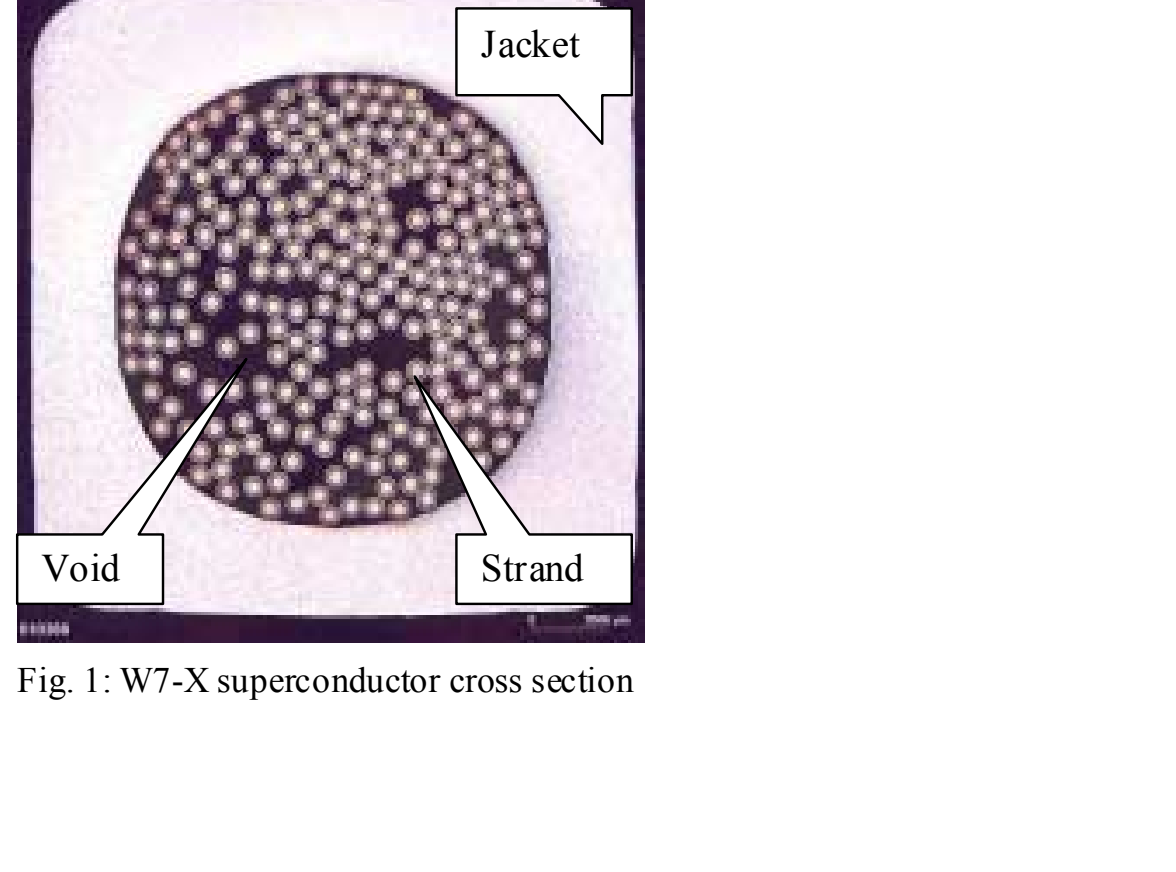


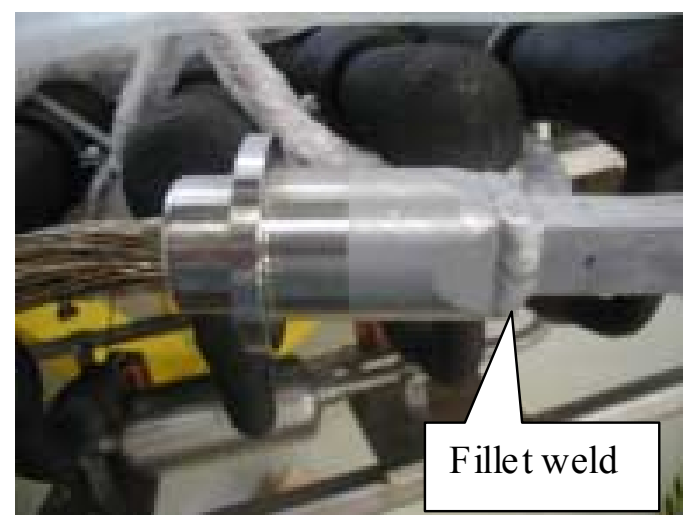

Fig. 2: Welded Al-St-transition piece 


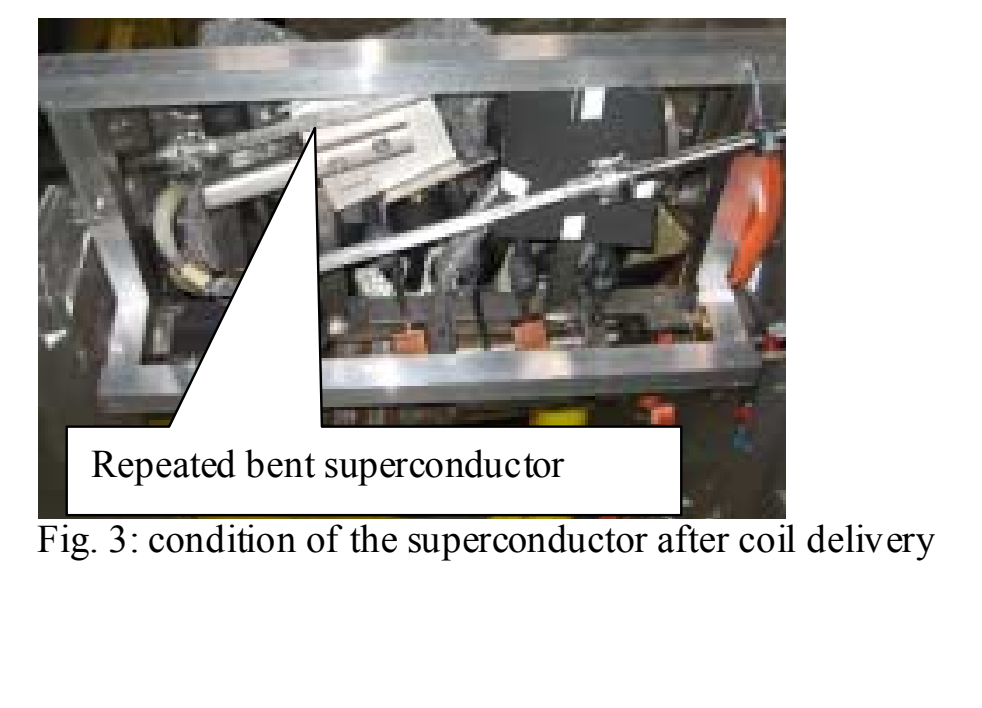

Repeated bent superconductor

Figure

Repeated bent superconductor

Repeated bent superconductor

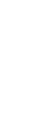

Repeated bent superconductor

.

.

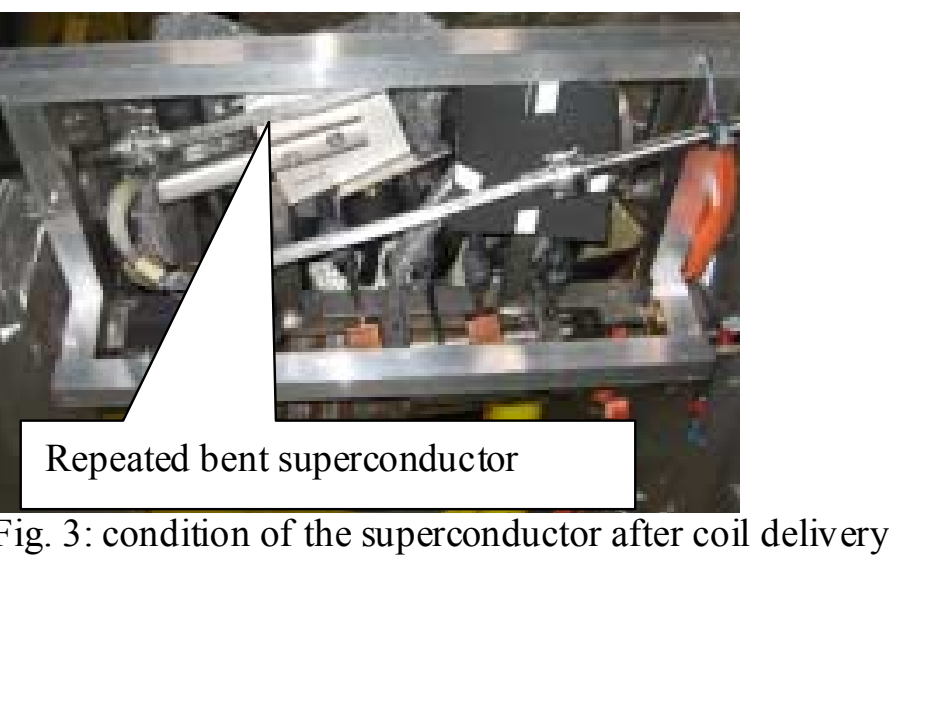




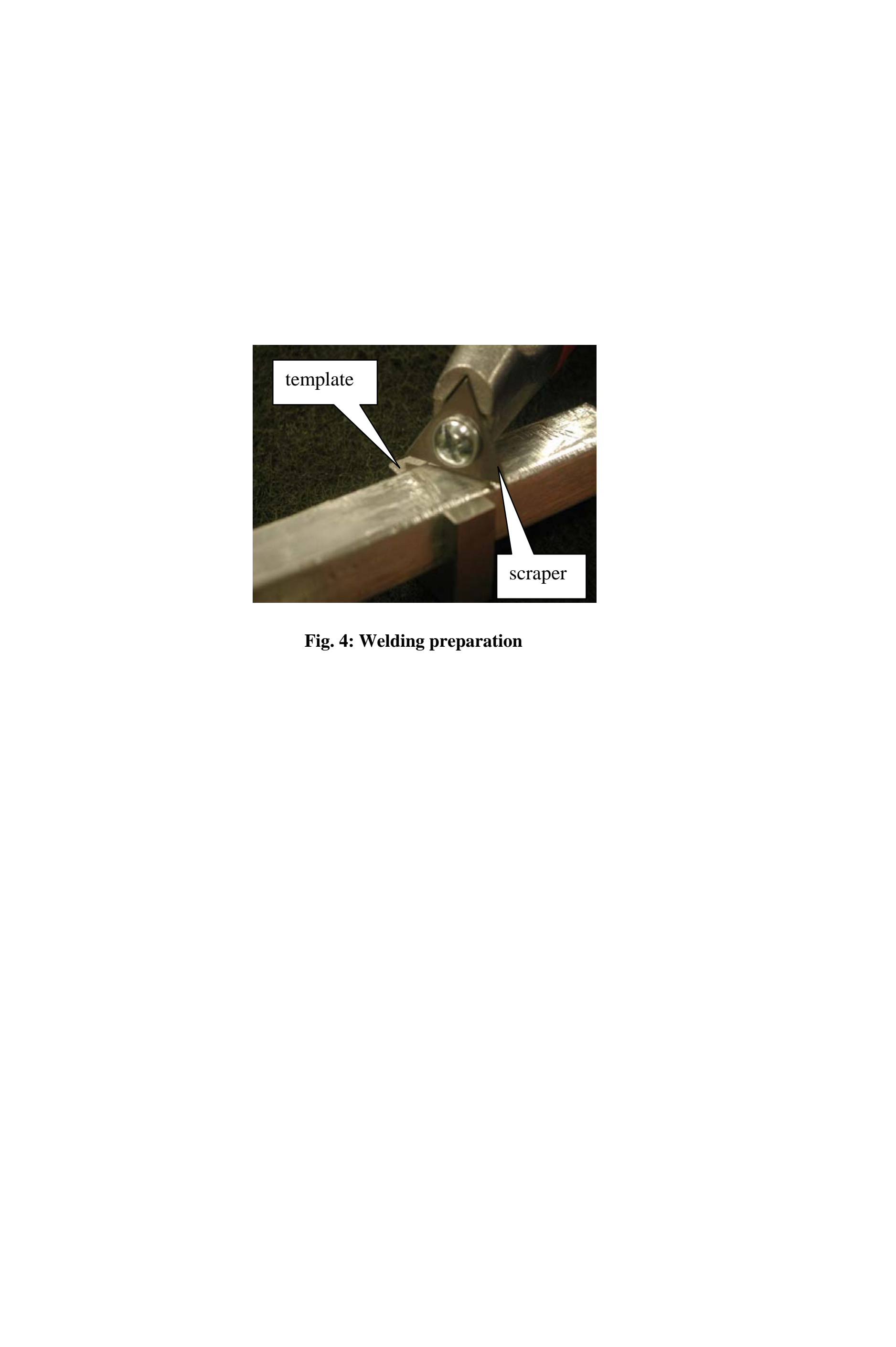

Fig. 4: Welding preparation

\author{
res. Welding preparation
}

template

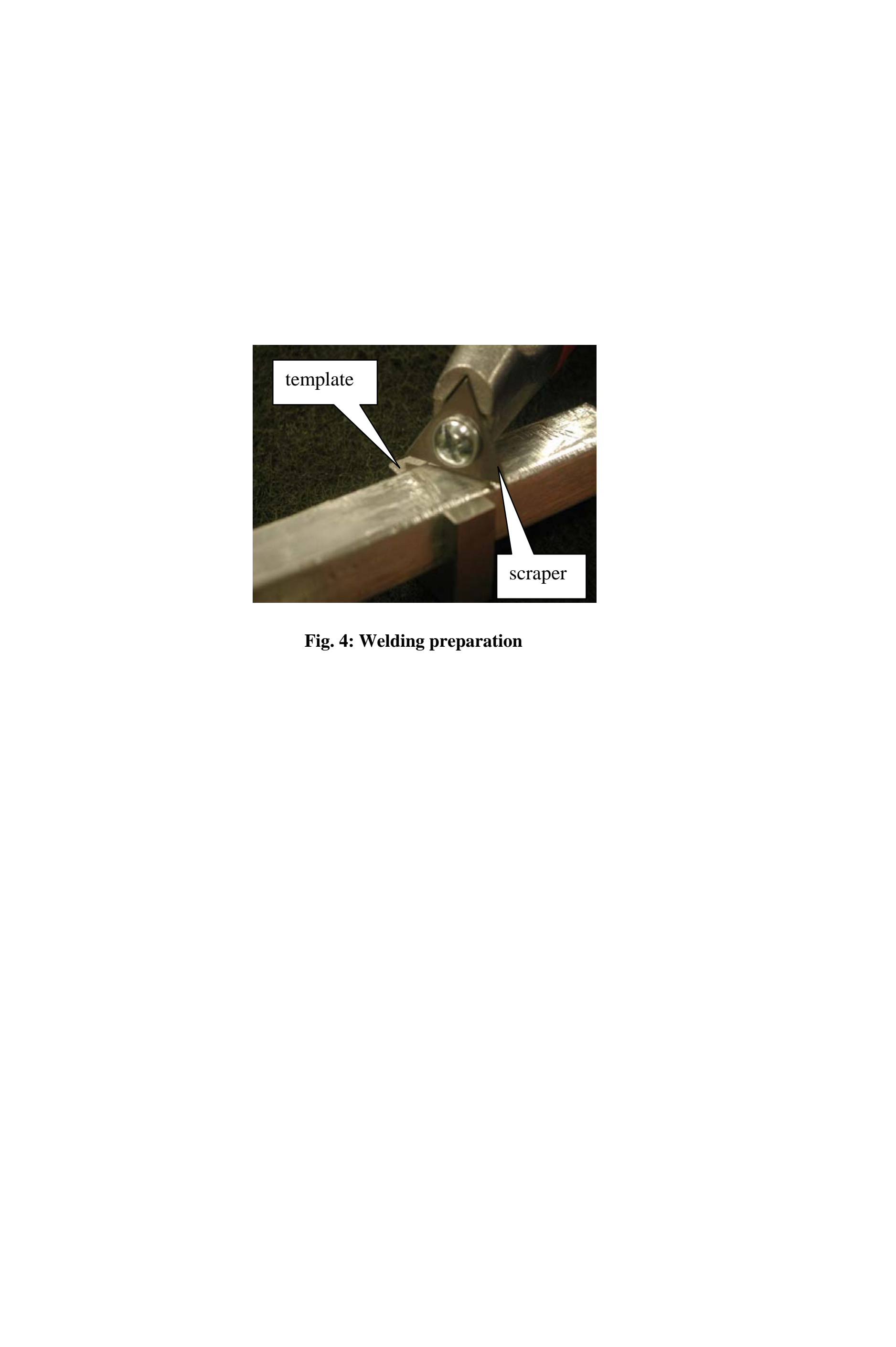

列

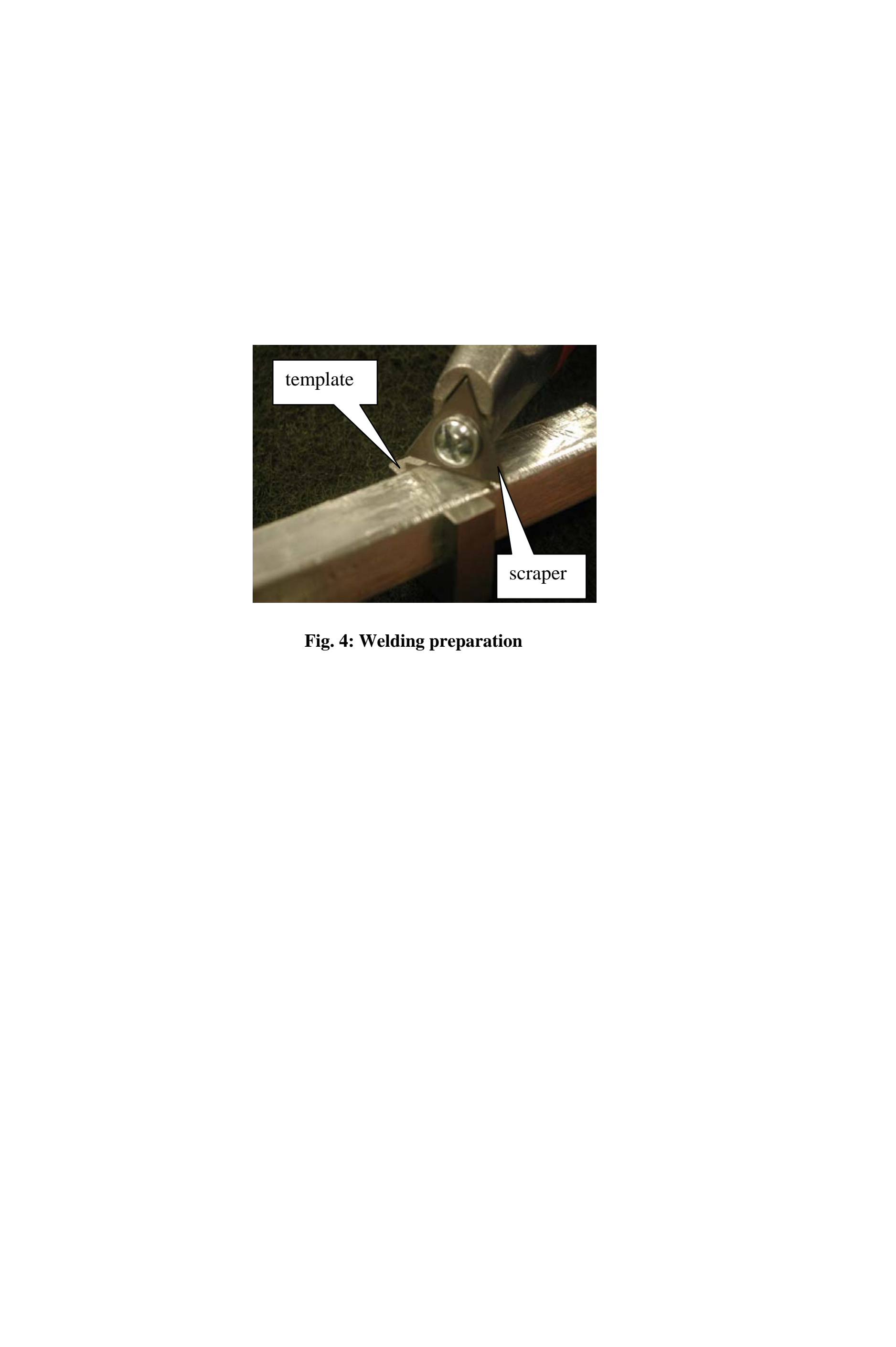

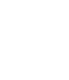
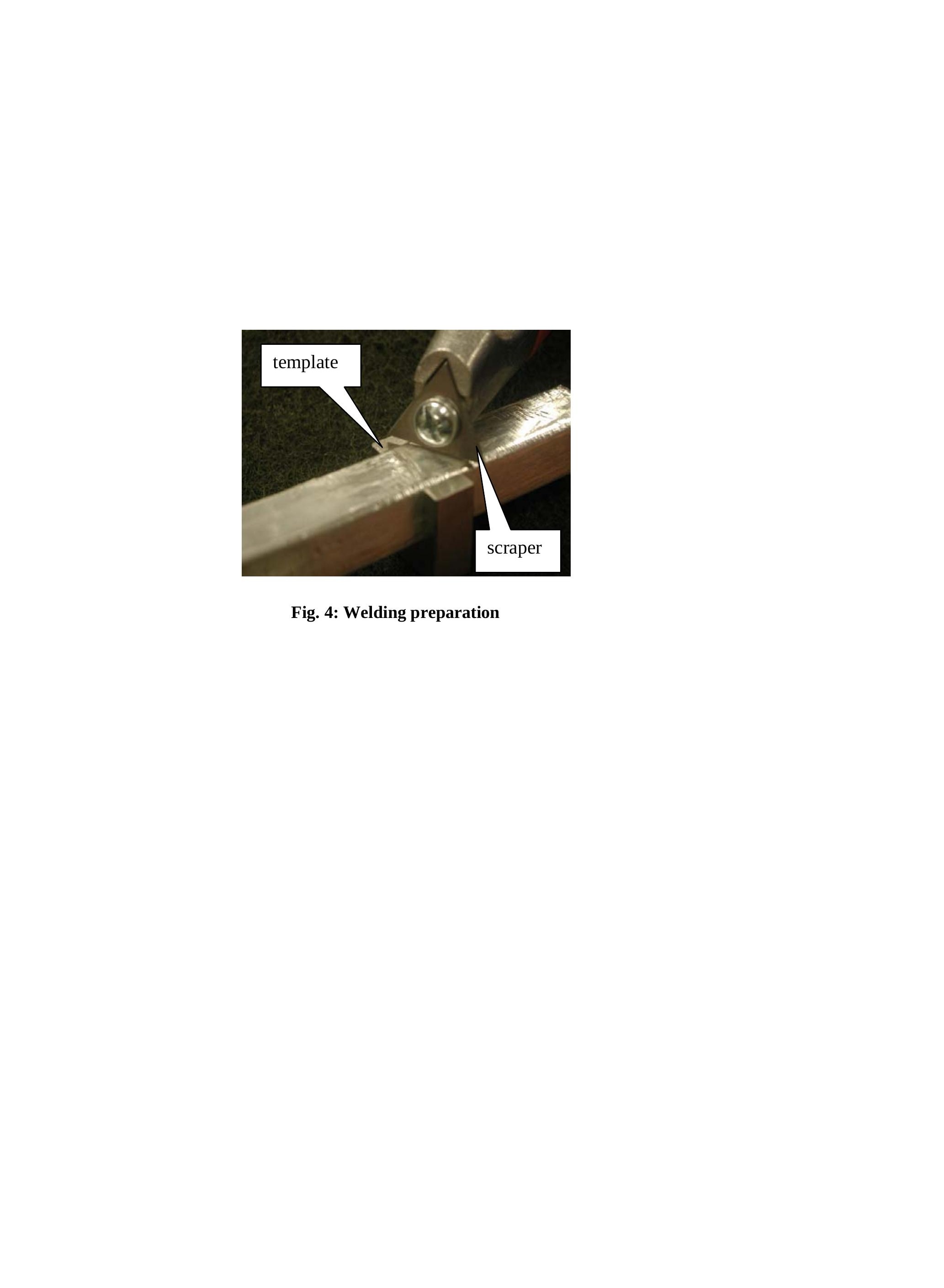


\begin{tabular}{|l|ll|}
\hline & & \\
\hline
\end{tabular}



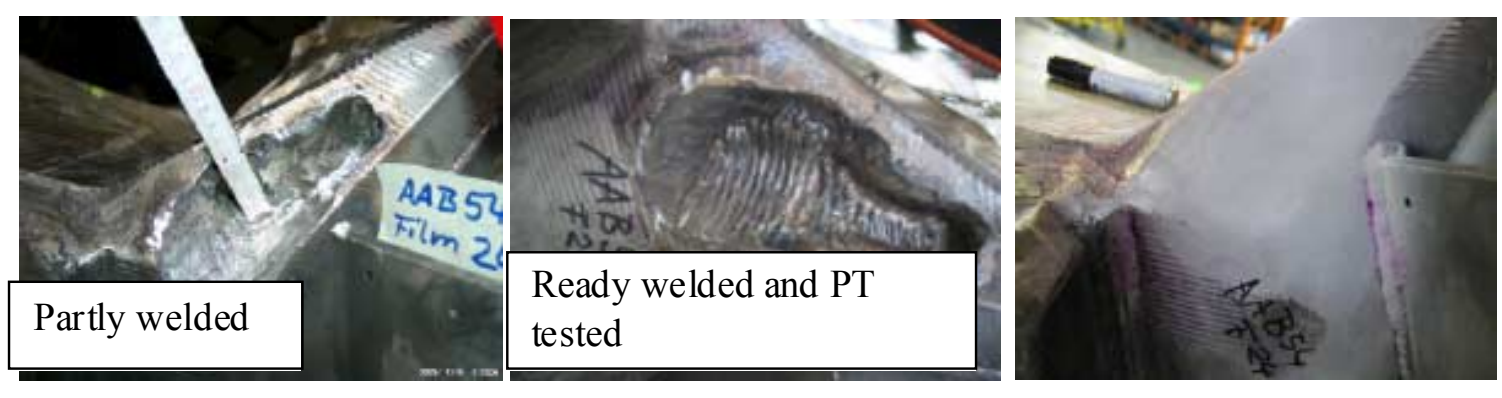

Fig. 9: Repair of a casing defect

\begin{tabular}{l} 
Grinded \\
\hline Partly welded \\
\hline
\end{tabular}

Ready welded and PT sted

repe

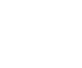

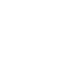

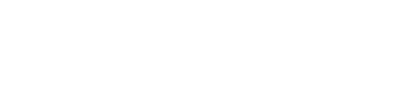

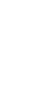

(n) 
Table 1: Imperfections and possible reasons

\begin{tabular}{|c|c|c|}
\hline Imperfection & Possible reason & Measure for prevention \\
\hline \multirow[t]{6}{*}{ Pores } & $\begin{array}{l}\text { Contamination outside of } \\
\text { the superconductor jacket }\end{array}$ & $\begin{array}{l}\text { Remove the oxide layer by scraping and clean } \\
\text { with Isopropanol afterwards. }\end{array}$ \\
\hline & $\begin{array}{l}\text { Humidity in the oxide layer } \\
\text { of the base and the filler } \\
\text { material }\end{array}$ & $\begin{array}{l}\text { Bake out in a vacuum oven (transition piece, } \\
\text { filler material) or in a specially developed } \\
\text { vacuum chamber (conductor jacket). Remove } \\
\text { the oxide layer by scraping (conductor jacket } \\
\text { and transition piece) or grinding fleece (filler } \\
\text { material). }\end{array}$ \\
\hline & High humidity in the air & $\begin{array}{l}\text { Measure and control the humidity values when } \\
\text { welding. }\end{array}$ \\
\hline & $\begin{array}{l}\text { High humidity in the } \\
\text { shielding gas }\end{array}$ & $\begin{array}{l}\text { Use austenitic steel pipes instead of gas hoses } \\
\text { and seal the connections. Provide enough flow } \\
\text { of the shielding gas before welding. }\end{array}$ \\
\hline & $\begin{array}{l}\text { Contamination by } \\
\text { environment and handling }\end{array}$ & $\begin{array}{l}\text { Use a clean workplace and clean tools. Touch } \\
\text { the welding area and the filler material only } \\
\text { with clean gloves. }\end{array}$ \\
\hline & $\begin{array}{l}\text { Limited outgassing of } \\
\text { hydrogen because of the } \\
\text { welding position }\end{array}$ & Avoid the overhead position. \\
\hline Cracks & $\begin{array}{l}\text { Gaps by geometrical } \\
\text { deviations of the jacket by } \\
\text { tolerances and previous } \\
\text { bending in the welding area }\end{array}$ & $\begin{array}{l}\text { Use transition pieces with smaller inner } \\
\text { dimension and adapt the outer superconductor } \\
\text { dimension by paring with a template. }\end{array}$ \\
\hline $\begin{array}{l}\text { Poor } \\
\text { penetration } \\
\text { (risk of leaks) }\end{array}$ & $\begin{array}{l}\text { Too low temperature of the } \\
\text { weld }\end{array}$ & $\begin{array}{l}\text { Preheat to } 70^{\circ} \mathrm{C} \text { and observe the WPS } \\
\text { concerning the welding parameters (current, } \\
\text { voltage, time). }\end{array}$ \\
\hline Melt through & Too much heat input & $\begin{array}{l}\text { Feed the wire continuously and observe the } \\
\text { WPS. Apply cooling with a cooling chamber. }\end{array}$ \\
\hline All & $\begin{array}{l}\text { Manual skill of the welder, } \\
\text { accessibility and welding in } \\
\text { difficult positions }\end{array}$ & $\begin{array}{l}\text { Training of the welders and preparation of proof } \\
\text { samples. }\end{array}$ \\
\hline
\end{tabular}


* Detailed Response to Reviewers
\[ \begin{array}{l}\text { Detailed response to reviewers: } \\ \text { Not necessary. No further comments. }\end{array} \]

* Detailed Response to Reviewers
\[ \begin{array}{l}\text { Detailed response to reviewers: } \\ \text { Not necessary. No further comments. }\end{array} \]

* Detailed Response to Reviewers
\[ \begin{array}{l}\text { Detailed response to reviewers: } \\ \text { Not necessary. No further comments. }\end{array} \]

(n)

Not necessary. No further comments.

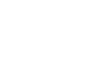

(n)

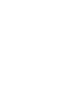

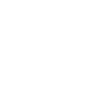

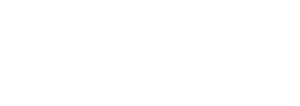

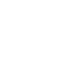

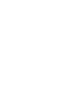

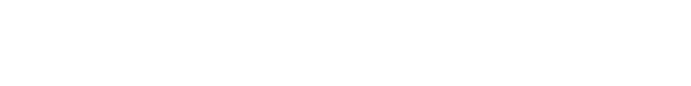

